\title{
Influencia de la velocidad de carga orgánica sobre el proceso de digestión anaerobia de aguas de lavado de aceitunas de almazara en reactores de lecho fluidizado
}

\author{
Por Rafael Borja ${ }^{1}$, José Alba ${ }^{1}$, Antonio Martín ${ }^{2}$ y Angela Mancha ${ }^{1}$ \\ 'Instituto de la Grasa (CSIC). Avda. Padre García Tejero, 4-41012 - Sevilla. \\ ${ }^{2}$ Departamento de Ingeniería Química. Facultad de Ciencias. Universidad de Córdoba. \\ Avda. San Alberto Magno, s/n. 14004 - Córdoba.
}

\section{RESUMEN}

\begin{abstract}
Influencia de la velocidad de carga orgánica sobre el proceso de digestión anaerobia de aguas de lavado de aceitunas de almazara en reactores de lecho fluidizado.
\end{abstract}

Se ha efectuado un estudio del proceso de digestión anaerobia en régimen continuo de aguas de lavado de aceitunas de almazara en un reactor de lecho fluidizado utilizando sepiolita como soporte de adhesión bacteriana a la temperatura de $35^{\circ} \mathrm{C}$. El biorreactor operó de modo satisfactorio utilizando concentraciones de alimento de $4,5,3,5,2,5$, y $1,5 \mathrm{~g}$ DQO/ en un rango de 4,5 a 1,25 días de tiempo de retención hidráulico (TRH). Se han obtenido porcentajes de eliminación de DQO entre el 50 y el $90 \%$ para velocidades de carga orgánica variables entre 0,46 y 2,25 g DQO/ día utilizando la concentración de alimento más elevada ( $S_{\circ}=4,5 \mathrm{~g} \mathrm{DQO} / \mathrm{l}$ ).

La DQO y acidez volátil de los efluentes se incrementaron de forma paralela al aumentar la velocidad de carga orgánica en el reactor, presentando esta última un máximo valor de $1,55 \mathrm{~g}$ ácido acético/l en el caso más desfavorable estudiado ( $S_{0}=4,5 \mathrm{~g}$ $D Q O / l$ y $T R H=1,25$ días). La subida de acidez volátil fue contrarrestada en todo momento por los elevados valores de alcalinidad (3440-4670 $\mathrm{mg} \mathrm{CaCO}_{3} /$ l) lo que determinó una alta estabilidad del proceso y que la relación acidez volátil/alcalinidad se mantuviera, salvo en el caso mencionado, por debajo del valor límite 0,3-0,4 por encima del cual el proceso anaerobio se desestabiliza.

El coeficiente de rendimiento de producción en metano del proceso fue de 0,28 I metano STP/g DQO eliminada.

PALABRAS-CLAVE: Aceituna - Aguas de lavado - Digestión anaerobia - Lecho fluidizado - Régimen continuo.

\section{SUMMARY}

Effect of organic loading rate on anaerobic digestion process of wastewaters from the washing of olives prior to the oil production process in a fluidized bed reactor.

A study of the anaerobic digestion process of wastewaters from the washing of olives prior to the oil production process was carried out in a fluidized bed reactor with sepiolite immobilised biomass at $35^{\circ} \mathrm{C}$. The bioreactor worked satisfactorily using influent $C O D$ concentrations of $4.5,3.5,2.5$ and $1.5 \mathrm{~g}$ COD/ for a hydraulic retention time (HRT) range of 4.5 to 1,25 days. COD removal efficiencies in the range $50-90 \%$ were achieved in the reactor, when evaluated at organic loading rates of between 0.46 and $2.25 \mathrm{~g}$ COD/ day using the highest influent substrate concentration ( $S_{0}=4.5 \mathrm{~g}$ COD/).

COD and volatile fatty acid (VFA) concentration were increased in parallel with the increase of organic loading rate in the reactor, VFA concentration showing a maximum value of $1.55 \mathrm{~g}$ acetic acid/l at the most unfavourable case studied ( $S_{0}=4,5 \mathrm{~g} C O D / /$ and HRT $=1.25$ days). The increase in effluent VFA concentrations was always counteracted by the high alkalinity values (3440-4670 $\mathrm{mg} \mathrm{CaCO} / /)$ which brought about the high stability of the process and values of the alkalinity/VFA ratio lower than 0.3-0.5, except for the above-mentioned case, limit value over which the anaerobic process is destabilized.

The yield coefficient of methane production was 0.28 I methane STP/g COD removed.

KEY-WORDS: Anaerobic digestion - Continuous regime Fluidized bed - Olive - Waste water from washing.

\section{INTRODUCCIÓN}

El uso de máquinas lavadoras de aceitunas se ha divulgado e instalado masivamente en los diez últimos años en las almazaras españolas.

El proceso de lavado se efectúa empleando exclusivamente agua procedente de la red pública. Las aceitunas se introducen en la máquina, y por medio de un borboteo de aire y/o de circulación forzada de agua, se someten a determinados movimientos cuyo objetivo es la eliminación de las impurezas adheridas y de las acompañantes.

El volumen de agua que utilizan estos equipos oscila entre 2 y $4 \mathrm{~m}^{3}$, en función de su capacidad de lavado horaria, recirculando dicho líquido al menos durante una jornada, dependiendo, como es lógico, del grado de suciedad (Alba, 1997).

Estas aguas, debido a su contenido y composición, se vierten generalmente a las balsas de evaporación y forman parte de los efluentes de la almazara, englobándose dentro de la denominación de «alpechín».

Como consecuencia de esta situación y de la transformación tecnológica producida en la elaboración por el uso del sistema de centrifugación de dos salidas, más comúnmente conocido por sistema de dos fases, se ha reducido enormemente la producción de alpechín y dado que los nuevos efluentes están básicamente constituidos por: aguas de lavado de aceitunas, aguas de lavado de aceite y aguas de lavado de instalaciones, se consideró interesante el profundizar en las características del agua de lavado de aceitunas, así como estudiar las posibilidades de su depuración utilizando sistemas biológicos. 
En este sentido, experimentos anteriores pusieron de manifiesto la viabilidad de procesos de depuración tanto aerobios (Borja et al., 1995) como anaerobios (Borja et al., 1994) para el tratamiento de estos efluentes. En el primer caso, utilizando procesos clásicos de fangos activados sin recirculación de lodos, se observaron eficiencias de eliminación de DQO superiores al $67 \%$ operando con 6 horas de tiempo de retención hidráulico a la temperatura de $14^{\circ} \mathrm{C}$. Los resultados mejoraron cuando se trabajó a $28^{\circ} \mathrm{C}$, obteniéndose velocidades máximas específicas de utilización de sustrato 11 veces superiores a las observadas en condiciones psicrófilas. La velocidad máxima específica de crecimiento bacteriano y la constante de saturación se vieron también influenciadas por la temperatura. Por otra parte, experimentos preliminares demostraron la aplicabilidad de procesos de depuración anaerobia en régimen discontinuo para el tratamiento de estos vertidos. En ellos, utilizando reactores de mezcla completa con biomasa adherida sobre sepiolita, se observó una considerable disminución de la constante cinética y de las actividades metanogénicas del proceso anaerobio al aumentar el grado de maduración de la aceituna. Los porcentajes medios de eliminación de materia orgánica (DQO) variaron entre $65 \%$ y $73 \%$, mientras que los coeficientes de rendimiento en metano oscilaron entre 0,263 y 0,298 I metano/g DQO eliminada.

Entre las principales ventajas que presentan los reactores de lecho fluidizado con soporte de sepiolita destacan:

- El pequeño tamaño de las partículas de soporte, lo que proporciona una elevada área específica sobre la que tiene lugar la adhesión de los microorganismos.

- Pueden alcanzarse concentraciones de biomasa más elevadas que en los sistemas de cultivo suspendidos.

- No se presentan los problemas de colmatación típicos de los biorreactores de lecho fijo que operan con elevadas concentraciones de biomasa.

- La turbulencia creada en estos sistemas aumenta la transferencia de materia por lo que en estos reactores pueden tratarse efluentes con baja carga (como los que se consideran en este trabajo) para los cuales la transferencia de materia es un factor limitante.

- La caída de presión que se produce en el lecho es baja, por lo que el coste de bombeo es reducido.

- Normalmente se obtienen efluentes con una pequeña cantidad de sólidos en suspensión, por lo que no se precisan grandes tanques de sedimentación para el efluente.

El objetivo de este trabajo es el de estudiar el proceso de depuración anaerobia de aguas de lavado de aceitunas de almazara, en régimen continuo, utilizando reactores de lecho fluidizado con sepiolita como soporte de adhesión bacteriana. Al mismo tiempo, se estudia la influencia de la velocidad de carga orgánica sobre los parámetros operacionales, de control del proceso y, en definitiva, sobre la estabilidad del mismo.

\section{PARTE EXPERIMENTAL}

\subsection{Características de las aguas de lavado}

Las aguas de lavado de aceitunas (variedad «Picual') proceden de los equipos de lavado previos a la línea de elaboración por centrifugación en dos fases instalados recientemente en la almazara experimental del Instituto de la Grasa. En la tabla I se resumen las características más destacables de las aguas de lavado originales $(\mathrm{DQO}=4,5 \mathrm{~g} / \mathrm{l})$. Las otras tres aguas residuales utilizadas, de concentración en DQO 3,5, 2,5 y 1,5 g/l, se obtuvieron diluyendo las aguas originales con agua destilada. Los parámetros de caracterización del residuo de partida, así como de los efluentes del proceso de digestión anaerobia se realizaron de acuerdo con el «Standard Methods for the Examination of Water and Wastewater" (American Public Health Association, 1985).

\subsection{Equipo experimental}

El reactor de lecho fluidizado utilizado está constituido por un cilindro de vidrio de $6 \mathrm{~cm}$ de diámetro interno y $40 \mathrm{~cm}$ de altura, con un volumen efectivo de 1 litro, al que se acopla una pieza troncocónica en la parte superior para facilitar la decantación de la biomasa, con el fin de evitar su pérdida con el efluente del proceso. El equipo se introduce en una cámara termostatizada a la temperatura de $35^{\circ} \mathrm{C}$. Como soporte para la adhesión de los microorganismos anaerobios reponsables del proceso se utiliza sepiolita, silicato magnésico de tamaño comprendido entre 0,4 y $0,8 \mathrm{~mm}$ de diámetro, que permite la fijación mayoritaria de bacterias metanogénicas (Maestrojuán y Fiestas, 1988). Su pequeña densidad aparente le hace especialmente apropiado para el desarrollo de procesos de depuración en este tipo de reactores (Borja et al., 1992). Para la determinación del volumen de metano producido durante el proceso se utilizó un depósito de 1 litro de capacidad tipo Mariotte acoplado al digestor. Previamente se intercala un borboteador perfectamente cerrado que contiene una solución de hidróxido sódico (3 M) para retener el dióxido de carbono producido durante el proceso. El metano originado desplaza al agua del depósito y por medida del volumen de ésta se conoce el metano obtenido. Otras características y detalles del equipo, referentes al sistema de bombeo del influente del proceso y de salida de efluentes a través de un cierre hidráulico están detalladas en un trabajo precedente (Borja et al., 1991). 


\subsection{Procedimiento experimental}

\section{Etapa de arranque y aclimatación}

Al reactor se añaden inicialmente $750 \mathrm{ml}$ de agua destilada, $250 \mathrm{ml}$ de un inóculo consistente en lodos procedentes de una balsa de vertido de alpechín debidamente diluidos y neutralizados y 10 gramos de sepiolita.

Previamente a la realización de los experimentos se llevó a cabo, durante un período de 1 mes, una etapa preliminar de aclimatación de la biomasa al sustrato objeto de estudio, tras la cual se desarrollaron una serie de experimentos en régimen discontinuo, añadiéndose al reactor volúmenes progresivos, desde 0,1 a 0,4 litros, de aguas de lavado de aceitunas de distinto grado de maduración con valores de DQO variables entre 2,8 y 5,5 g/l (Borja et al., 1994).

\section{Desarrollo de los experimentos en régimen continuo}

Tras estas etapas preliminares, se realizaron cuatro series de experimentos en régimen continuo, en los que se utilizaron aguas de lavado con valores de DQO de 4,5 g/l (Tabla I), 3,5, 2,5 y 1,5 $\mathrm{g} /$. Para cada uno de estos cuatro influentes, el reactor operó con caudales de alimentación de 0,222 , $0,285,0,400,0,500,0,666$ y $0,800 \mathrm{l} / \mathrm{d}$ ía que corresponden a $4,5,3,5,2,5,2,0,1,5$ y 1,25 días de tiempo de retención hidráulico respectivamente. La concentración de sólidos en suspensión volátiles que se asimiló a la biomasa bacteriana permaneció prácticamente constante para cada una de las alimentaciones utilizadas, presentado los valores medios de $11,2,11,4,11,5$ y $11,7 \mathrm{~g}$ de sólidos en suspensión volátiles (SSV)/l para los influentes con DQO 4,5, 3,5, 2,5 y 1,5 g/l, respectivamente.

Para cada caudal se determinan, tras alcanzarse condiciones de estado estacionario con respecto a la concentración de sustrato, el volumen de metano producido diariamente, el $\mathrm{pH}$, la DQO, acidez volátil y alcalinidad de los efluentes obtenidos. Las muestras de efluentes se tomaron y analizaron durante al menos 5 días consecutivos. Se consideraron como valores correspondientes al estado estacionario las medias de estas determinaciones cuando las desviaciones entre los valores observados fueron inferiores o iguales al $3 \%$. Todos los experimentos se realizaron por duplicado y los valores medios se recogen en las tablas y figuras correspondientes.

Las velocidades de carga orgánica utilizadas en las cuatro series de experimentos se aplicaron de forma gradual y creciente con objeto de minimizar los efectos de "choque" que podrían producirse en caso de aumento brusco en la carga adicionada.
Tabla I

Características de las aguas de lavado de aceitunas utilizadas ${ }^{\star}$

\begin{tabular}{lc}
\hline \multicolumn{1}{c}{ Parámetro } & Concentración \\
\hline $\mathrm{pH}$ & 5,9 \\
Demanda química de oxígeno (DQO) & $4,50 \mathrm{~g} / \mathrm{l}$ \\
Demanda biológica de oxígeno $\left(\mathrm{DBO}_{5}\right)$ & $3,45 \mathrm{~g} / \mathrm{l}$ \\
Nitrógeno amoniacal $\left(\mathrm{NH}_{4}^{+}\right)$ & $0,015 \mathrm{~g} / \mathrm{l}$ \\
Acidez volátil (ácido acético) & $0,62 \mathrm{~g} / \mathrm{l}$ \\
Alcalinidad & $0,48 \mathrm{~g} / \mathrm{l}$ \\
Sólidos totales & $4,52 \mathrm{~g} / \mathrm{l}$ \\
Sólidos minerales & $1,50 \mathrm{~g} / \mathrm{l}$ \\
Sólidos volátiles & $3,02 \mathrm{~g} / \mathrm{l}$ \\
Sólidos en suspensión totales & $1,75 \mathrm{~g} / \mathrm{l}$ \\
Sólidos en suspensión minerales & $1,07 \mathrm{~g} / \mathrm{l}$ \\
Sólidos en suspensión volátiles & $0,68 \mathrm{~g} / \mathrm{l}$ \\
Fenoles totales (ácido cafeico) & $0,06 \mathrm{~g} / \mathrm{l}$ \\
\hline
\end{tabular}

* Los valores detallados son las medias de 4 determinaciones, siendo las desviaciones entre las medidas efectuadas inferiores al $3 \%$ en todos los casos.

\section{RESULTADOS Y DISCUSIÓN}

En las tablas II, III y IV se detallan los valores de la concentración de sustrato en los efluentes, del volumen de metano producido diariamente y $\mathrm{pH}$, respectivamente, para cada uno de los experimentos realizados con las cuatro concentraciones de sustrato utilizadas como alimento.

Como se observa en la tabla IV, el pH se mantiene en todos los casos dentro del intervalo óptimo $(6,8-7,6)$ para el adecuado y eficaz desarrollo de las bacterias metanogénicas (Fannin, 1987), a excepción del experimento correspondiente al menor tiempo de retención utilizado, 1,25 días, y concentración máxima de sustrato en la alimentación, 4,5 g DQO/l, que se corresponde con la situación más extrema de todas las consideradas en este diseño experimental. En consecuencia, un tiempo de retención hidráulico inferior a 1,25 días (30 horas) podría dar lugar a una acidificación del reactor cuando se opera con concentraciones de sustrato en el alimento de $4,5 \mathrm{~g}$ DQO/l. Para este tiempo de retención y concentración de sustrato en el influente se observó, como se aprecia en la tabla III, una bajada en la producción diaria de metano $(0,48 \mathrm{l} / \mathrm{d}$ ía) con respecto al tiempo de retención inmediatamente superior estudiado (1,5 días), en el que fue de 0,491 l/día. Para los otros tres influentes, también se produjo un descenso paulatino del $\mathrm{pH}$ al disminuir el tiempo de retención; pero, en ningún caso, tuvo lugar una disminución por debajo de 6,8 . 
Tabla II

Variación de la concentración de sustrato en el efluente, $S_{e}(g$ DQO/l) para cada experimento realizado

\begin{tabular}{ccccc}
\hline $\begin{array}{c}\text { TRH } \\
\text { (días) }\end{array}$ & $S_{0}=4,5 \mathrm{~g} / 1$ & $S_{0}=3,5 \mathrm{~g} / 1$ & $S_{0}=2,5 \mathrm{~g} / 1$ & $S_{0}=1,5 \mathrm{~g} / \mathbf{l}$ \\
\hline 4,5 & 0,460 & 0,395 & 0,145 & 0,130 \\
3,5 & 0,680 & 0,540 & 0,205 & 0,185 \\
2,5 & 1,060 & 0,840 & 0,420 & 0,310 \\
2,0 & 1,450 & 1,010 & 0,610 & 0,430 \\
1,5 & 1,950 & 1,240 & 0,990 & 0,600 \\
1,25 & 2,25 & 1,730 & 1,210 & 0,800 \\
\hline
\end{tabular}

Tabla III

Volumen de metano producido diariamente (I/día) en función del tiempo de retención hidráulico (TRH, días) para cada una de las distintas concentraciones de aguas de lavado utilizadas

\begin{tabular}{ccccc}
\hline $\begin{array}{c}\text { TRH } \\
\text { (días) }\end{array}$ & $S_{0}=4,5 \mathrm{~g} / 1$ & $S_{0}=3,5 \mathrm{~g} / \mathbf{l}$ & $\mathrm{S}_{0}=2,5 \mathrm{~g} / \mathrm{l}$ & $\mathrm{S}_{0}=1,5 \mathrm{~g} / \mathbf{l}$ \\
\hline 4,5 & 0,280 & 0,220 & 0,165 & 0,095 \\
3,5 & 0,340 & 0,270 & 0,200 & 0,120 \\
2,5 & 0,420 & 0,330 & 0,250 & 0,145 \\
2,0 & 0,470 & 0,360 & 0,280 & 0,160 \\
1,5 & 0,491 & 0,395 & 0,305 & 0,165 \\
1,25 & 0,480 & 0,375 & 0,295 & 0,150 \\
\hline
\end{tabular}

Tabla IV

Variación del pH de los efluentes en función del tiempo de retención hidráulico (TRH, días) para cada una de las distintas concentraciones de aguas de lavado utilizadas

\begin{tabular}{ccccc}
\hline $\begin{array}{c}\text { TRH } \\
\text { (días) }\end{array}$ & $S_{0}=4,5 \mathrm{~g} / \mathbf{l}$ & $\mathrm{S}_{0}=\mathbf{3 , 5} \mathbf{g} / \mathbf{l}$ & $\mathrm{S}_{0}=\mathbf{2 , 5} \mathbf{g} / \mathbf{l}$ & $\mathrm{S}_{0}=\mathbf{1 , 5} \mathbf{g} / \mathbf{l}$ \\
\hline 4,5 & 7,6 & 7,4 & 7,3 & 7,4 \\
3,5 & 7,6 & 7,4 & 7,2 & 7,3 \\
2,5 & 7,6 & 7,2 & 7,0 & 7,3 \\
2,0 & 7,5 & 7,1 & 7,0 & 7,0 \\
1,5 & 7,2 & 7,0 & 6,9 & 7,0 \\
1,25 & 6,7 & 6,8 & 6,9 & 6,95 \\
\hline
\end{tabular}

En la figura 1 se representa el porcentaje de DQO eliminada en función de la velocidad de carga orgánica, $\mathrm{C}_{\mathrm{v}}$ (g DQO/I día), añadida al reactor para las cuatro concentraciones de alimento utilizadas. Para todas ellas, se observa una disminución lineal de la eficiencia de eliminación de sustrato con el aumento de la velocidad de carga orgánica. Se apreciaron eficiencias superiores al 56\% para cargas de 3,6 g DQO/l día.
La figura 2 muestra la variación de la velocidad de consumo de sustrato (g DQO/l día) con la velocidad de carga orgánica, $\mathrm{C}_{\mathrm{v}}$. Como se observa, aunque la eficiencia de eliminación de DQO disminuye con el aumento de la velocidad de carga orgánica, el sistema es capaz de seguir eliminando sustrato a mayores velocidades.

Los valores de la DQO de la salida del digestor se incrementan al crecer la velocidad de carga orgánica 
(Figura 3). De forma similar, la acidez volátil de los efluentes tuvo una variación paralela e idéntica con la carga orgánica (Figura 4), observándose una subida gradual con la velocidad de carga. La tendencia es la misma que la observada con los valores de DQO. Esto indica que, sobre todo
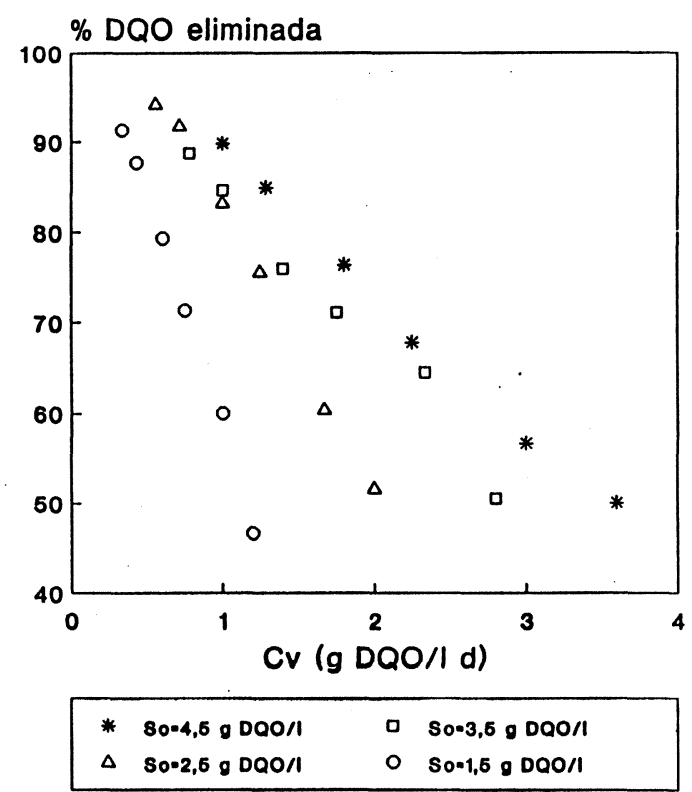

Figura 1

Efecto de la velocidad de carga orgánica, $C_{v}$, sobre la eficiencia de eliminación de DQO

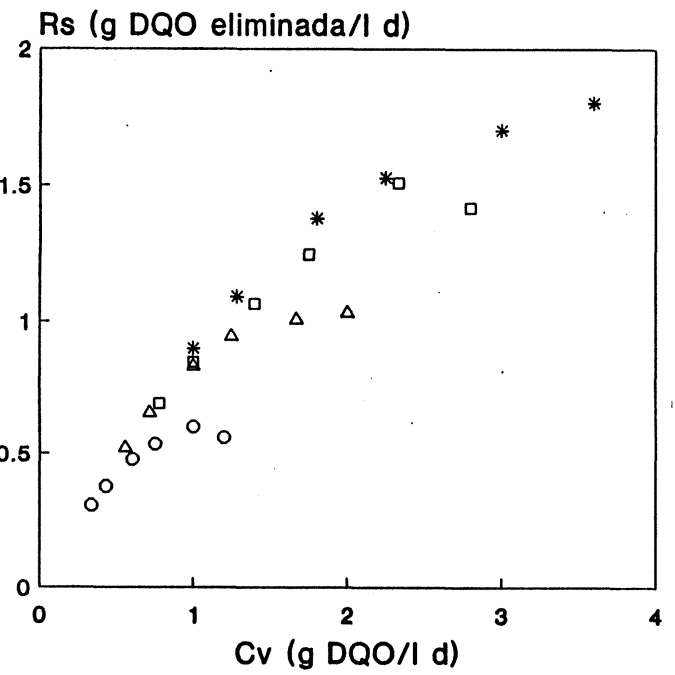

\begin{tabular}{|llll|}
\hline$*$ So-4,6 g DQO/I & व & So-3,6 g DQO/I \\
$\Delta$ & $S 0-2,6$ g DQO/I & $\circ$ & $S 0-1,6 \mathrm{~g}$ DQO/I \\
\hline
\end{tabular}

Figura 2

Variación de la velocidad de eliminación de sustrato, $R_{\mathbf{8}}$, con la velocidad de carga orgánica, $C_{v}$

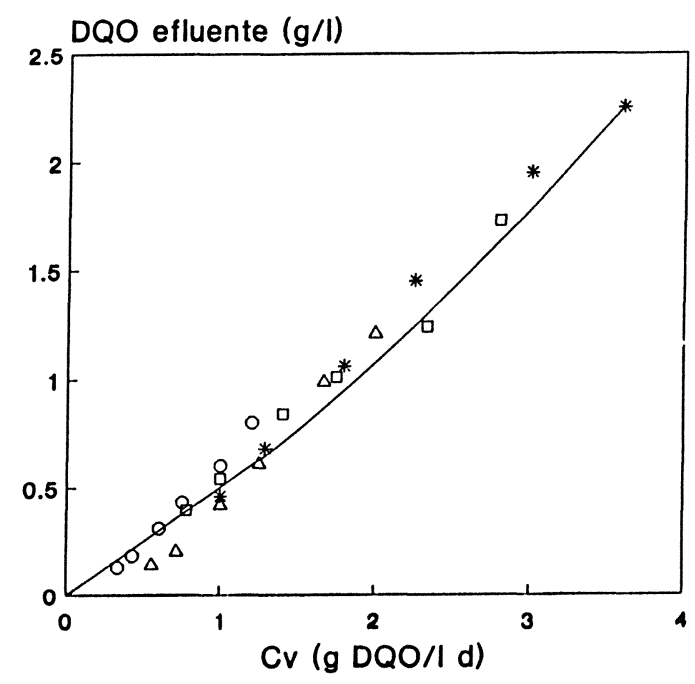

\begin{tabular}{|c|c|c|c|}
\hline * & So-4,6 O DQO/I & 口 & $S 0 \cdot 3,6, D Q O / I$ \\
\hline$\Delta$ & $S 0=2,6, D Q O / 1$ & 0 & So-1,6 g DQO/I \\
\hline
\end{tabular}

Figura 3

Variación de la DQO del efluente con la velocidad de carga orgánica, $\mathrm{C}_{\mathrm{v}}$
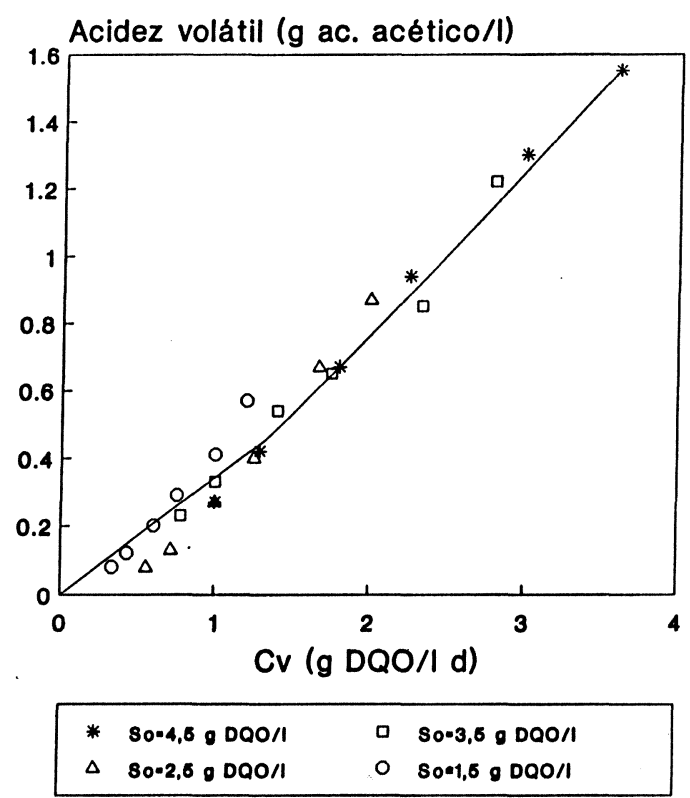

Figura 4

Efecto de la velocidad de carga orgánica, $C_{v}$, sobre la concentración de ácidos volátiles en el efluente

para elevadas velocidades de carga, la DQO de los efluentes es mayoritariamente debida a la acumulación de ácidos volátiles sin digerir en el reactor.

La acidez volátil es uno de los parámetros de control de más importancia y quizás el más específi- 
co del proceso de depuración anaerobia. La acumulación de ácidos volátiles en el digestor es síntoma inequívoco de desestabilización causada por un desacople en las cinéticas de las reacciones de producción y eliminación de los mismos. Los ácidos orgánicos volátiles actúan como inhibidores del proceso anaerobio. Aunque existe controversia, parece que la presencia de ácidos volátiles no ionizados es la causa fundamental de la inhibición (Fannin, 1987). En este sentido, el pH juega un papel determinante. Estos ácidos, mayoritariamente el acético, pueden estar en forma molecular o disociados. Este fenómeno inhibidor puede explicarse al considerar que muchas bacterias son relativamente impermeables al paso de $\mathrm{H}^{+}, \mathrm{CH}_{3}-\mathrm{COO}^{-}$y $\mathrm{OH}^{-}$, mientras que toleran el paso a través de su membrana celular, del $\mathrm{CH}_{3}-\mathrm{COOH}$ no disociado. Este acético incorporado al interior de la célula se disocia y modifica el pH interno, causando la inhibición.

En un reactor maduro estable, la concentración de ácidos volátiles es inferior a $500 \mathrm{mg} / \mathrm{l}$. Sin embargo, con adecuado control de $\mathrm{pH}$ no se alcanza inhibición hasta $5000 \mathrm{mg} / \mathrm{l}$. En nuestro caso, para todas las concentraciones de sustrato utilizadas como alimento y valores del tiempo de retención superiores a 2 días, el valor de la acidez volátil se mantuvo siempre por debajo de $500 \mathrm{mg}$ acético/l. Para valores de tiempo de retención inferiores a 2 días, la acidez volátil alcanzó valores algo superiores a 1000 ppm. Sin embargo, sólo en el caso del influente más concentrado $\left(\mathrm{S}_{\circ}=4,5 \mathrm{~g} \mathrm{DQO} / \mathrm{l}\right)$, el proceso continuó siendo bastante estable, debido a los elevados valores de alcalinidad (3440-4480 $\mathrm{mg} \mathrm{CaCO} / \mathrm{l})$ observados en todo momento en los efluentes del reactor. En con- secuencia, el aumento en la acidez volátil del sistema al aumentar la carga orgánica en el reactor se contrarrestó con los altos valores de alcalinidad y, en definitiva, por el adecuado poder tampón observado en el mismo. Por tanto, los datos obtenidos en estos experimentos demuestran que una alcalinidad superior a $3400 \mathrm{mg} / \mathrm{l}$ (expresada como $\mathrm{CaCO}_{3}$ ) es suficiente para impedir un descenso del $\mathrm{pH}$ por debajo de 6,7 , valor mínimo observado para el tiempo de retención más pequeño (1,25 días) y la concentración de sustrato alimentada más elevada (4,5 g DQO/I).

Por otra parte, en el "Manual of Practice» de la "Water Pollution Control Federation" (W.P.C.F., 1967) se advierte que, cuando la relación acidez volátil/alcalinidad sobrepasa el valor 0,3-0,4, el digestor probablemente se acidificará. En la figura 5 se representan los valores de esta relación para los distintos tiempos de retención y concentraciones de influente utilizadas. Como se observa, se produce un incremento de esta relación al disminuir el tiempo de retención, sobrepasándose muy ligeramente el valor de $0,4(0,45)$ en el experimento correspondiente a un tiempo de retención de 1,25 días y concentración de sustrato en el alimento de $4,5 \mathrm{~g}$ DQO/l. Aunque se produce un ligero descenso en el caudal de metano generado (tabla III), en ningún momento se advierte una desestabilización aparente del sistema, tal y como se aprecia por el pequeño descenso del $\mathrm{pH}(6,7)$ y por la normalidad observada en los experimentos efectuados con posterioridad a concentraciones de alimentación de 3,5, 2,5 y 1,5 g DQO/I.

En la figura 6 se representa la variación del porcentaje de DQO eliminada con el tiempo de retención hidráulico para cada uno de los alimentos ensayados.

\section{Ac. volátil/alcalinidad}

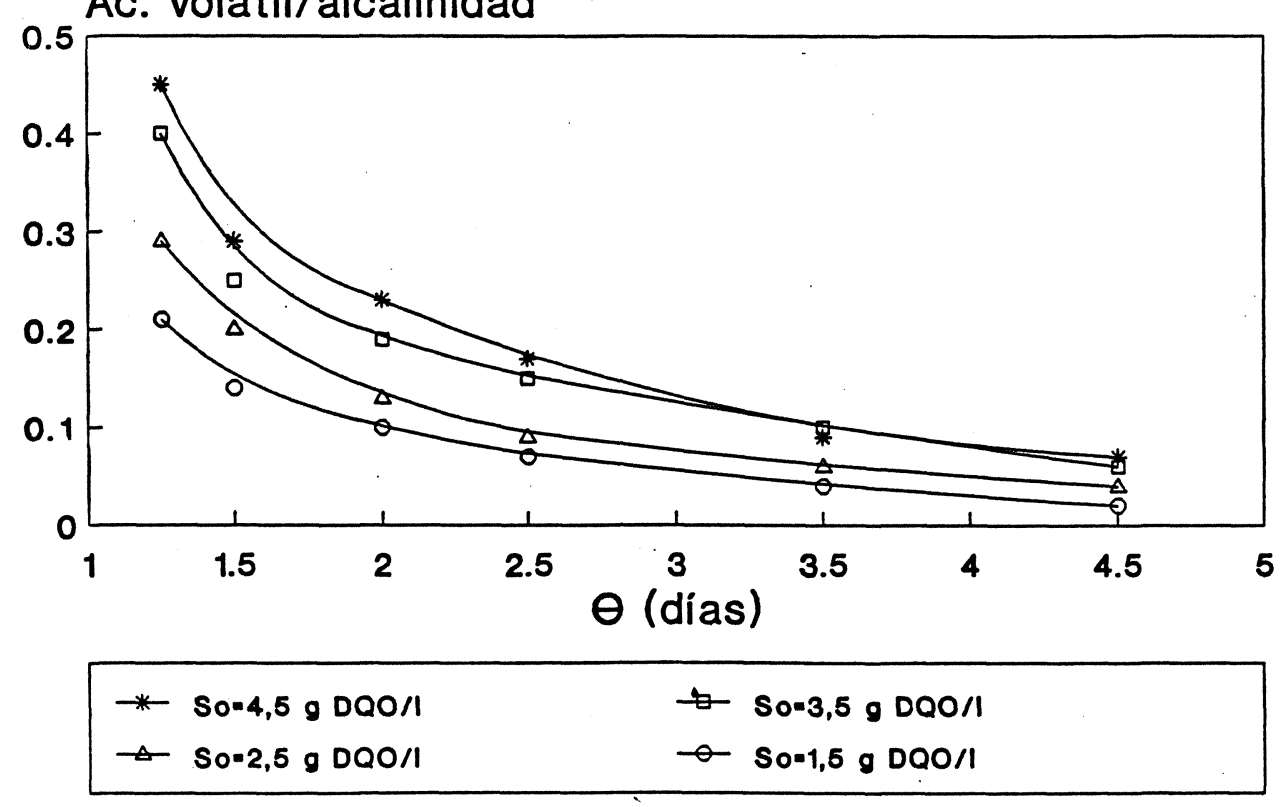

Figura 5

Variación de la relación acidez volátil/alcalinidad con el tiempo de retención hidráulico 


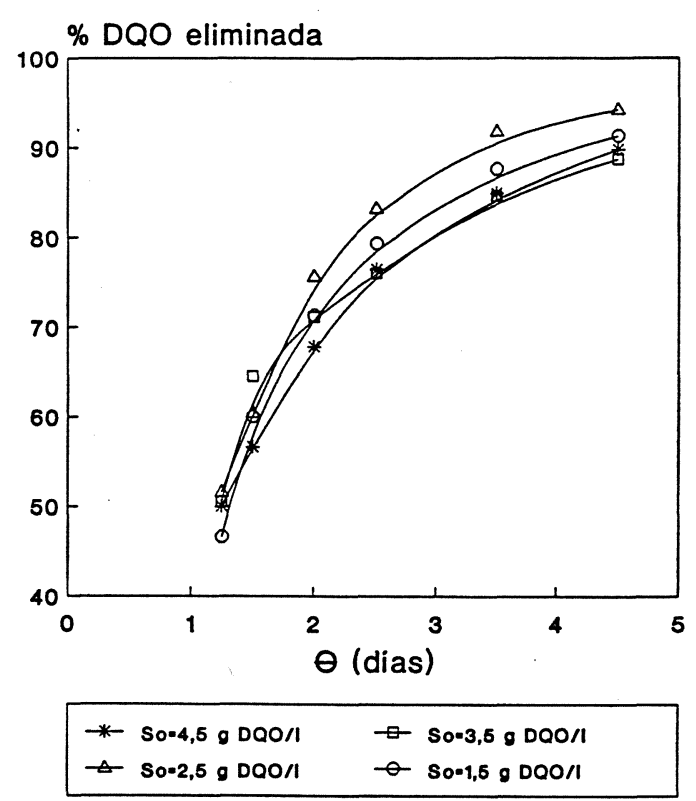

Figura 6

Variación de la eficiencia de eliminación de DQO con el tiempo de retención hidráulico
En los cuatro casos estudiados se produce un descenso de la eficiencia del proceso al disminuir el tiempo de retención de 4,5 a 2,0 días. Este descenso en el porcentaje de materia orgánica degradada se hace mucho más acusado para tiempos de retención inferiores a 2 días. También puede desprenderse de esta gráfica que el comportamiento del reactor, en cuanto a capacidad de eliminación de DQO se refiere, está sólo ligeramente influenciada por la concentración del sustrato en la alimentación.

Finalmente, a partir de los valores experimentales de eliminación de DQO y del volumen de metano generado por día (tablas II y III) se ha obtenido el coeficiente de rendimiento en metano del proceso (figura 7). Representando las parejas de valores [caudal de metano, $V_{g}(1 / d i ́ a)$, gramos de DQO eliminada, $\left(q\left(S_{0}-S\right)\right)$ de todos los experimentos realizados se ha obtenido a través de la pendiente de esta representación lineal, utilizando el método de mínimos cuadrados, el coeficiente de rendimiento en metano, cuyo valor fue de 0,28 I metano STP/g DQO eliminada. Este valor es ligeramente superior al obtenido en el tratamiento anaerobio, en régimen continuo, de alpechines de distinta concentración (DQO variable entre 5 y $40 \mathrm{~g} / \mathrm{l}$ ) (Martín et al., 1991) y es del mismo orden que los observados en el proceso de digestión anaerobia de otras aguas residuales de carácter orgánico (Chen y Hashimoto, 1978).

\section{CONCLUSIONES}

- Las aguas residuales procedentes del lavado de aceitunas de almazara son fácilmente biodegradables, vía anaerobia, utilizando reactores de lecho fluidizado con sepiolita como soporte para la inmovilización de los microorganismos responsables del proceso. Se obtienen porcentajes de eliminación de DQO entre el 50 y el $90 \%$ para velocidades de carga orgánica variables entre 0,46 y $2,25 \mathrm{~g} \mathrm{DQO} / \mathrm{l}$ día, utilizando concentraciones de sustrato en la alimentación de 4,5g DQO/l.

- El reactor opera de modo satisfactorio utilizando concentraciones de alimento $\left(S_{\circ}\right)$ de 4,5, 3,5, 2,5 y $1,5 \mathrm{~g} \mathrm{DQO} / \mathrm{l}$ en un rango de 4,5 a 1,25 días de tiempo de retención hidráulico (TRH).

- Con excepción del caso más extremo estudiado ( $\mathrm{S}_{\mathrm{o}}=4,5 \mathrm{~g}$ DQO/l y TRH $=1,25$ días) el proceso muestra una gran estabilidad, como se desprende de los pequeños valores de la relación acidez volátil/alcalinidad de los efluentes, en todos los casos, excepto en el ya mencionado, por debajo del valor límite $(0,3-0,4)$ a partir del cual el proceso anaerobio se desestabiliza. Igualmente, el pH de los efluentes se mantiene dentro del intervalo óptimo $(6,8-7,6)$ para el adecuado y eficaz desarrollo de las bacterias metanogénicas.

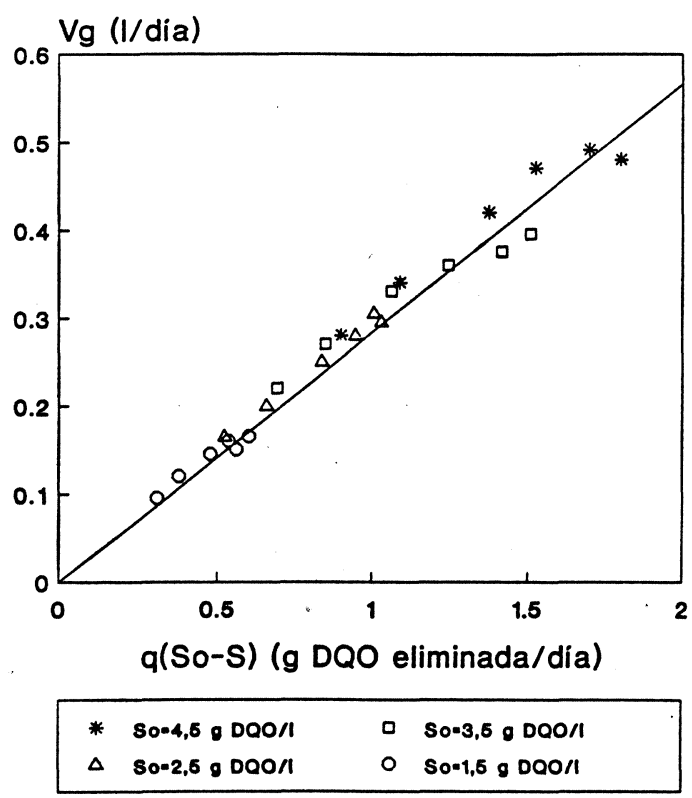

Figura 7

Determinación del coeficiente de rendimiento en metano 
- El coeficiente de rendimiento de producción en metano es de 0,28 I metano STP/g DQO eliminada.

\section{AGRADECIMIENTOS}

Queremos hacer constar nuestro agradecimiento a la Unión Europea (Proyecto AIR3-CT94-1355) y a la Junta de Andalucía por su ayuda para la realización de estos estudios; y a D. ${ }^{a}$ Carmen Sánchez por su eficaz ayuda y colaboración en la parte experimental.

\section{BIBLIOGRAFÍA}

Alba, J. (1997). -«Elaboración de aceite de oliva virgen».En: «El cultivo del olivo». Ed. D. Barranco, D. Fernández y L. Rallo. Junta de Andalucía. Consejería de Agricultura y Pesca, 509-537.

American Public Health Association, APHA. (1985). - «Standard Methods for the Examination of Water and Wastewater" (16th edn.)".- APHA, Washington, D.C.

Borja, R., Martín, A. y Fiestas, J. A. (1991). - «Influencia de la concentración de sustrato sobre la cinética del proceso de biometanización de alpechín en biorreactores de lecho fluidizado". - Grasas y Aceites 42, 363-370.

Borja, R., Martín, A., Durán, M. M. y Luque, M. (1992). - Estudio cinético de la depuración anaerobia de las aguas residuales de una industria quesera".- Revista
Española de Ciencia y Tecnología de los Alimentos 32, 19-32.

Borja, R., Alba, J. e Hidalgo, F. (1994). -«Digestión anaerobia de las aguas de lavado de aceitunas de almazara: influencia del período de recolección sobre la cinética del proceso".- Grasas y Aceites 45, 126-131.

Borja, R., Banks, C. J., Alba, J. and Escobar, J. P. (1995) - "The temperature dependence of the kinetic parameters derived for the aerobic treatment of wastewater from the washing of olives prior to the oil production process".J. Environ. Sci. Health A30, 8, 1693-1705.

Chen, Y. R. and Hashimoto, A.G. (1978). -«Kinetics of methane fermentation".-Biotechnology and Bioengineering 8, 269-282.

Fannin, K. F. (1987). -«Start-up, operation, stability and control». En: «Anaerobic digestion of biomass».-Eds.: D. P. Chynoweth and R. Isaacson, Elsevier Applied Science, 171-196.

Maestrojuán, G. M. and Fiestas, J. A. (1988). -«A study of behaviour of anaerobic bacteria in the presence of diverse materials usable as support".- Proceedings of $V$ International Symposium on Anaerobic Digestion, Bologna, Italy, 129-132.

Martín, A., Borja, R., García, I. and Fiestas, J. A. (1991). « «Kinetics of methane production from olive mill wastewater".Process Biochemistry, 26, 101-107.

Water Pollution Control Federation (WPCF). (1967). -«Anaerobic studge digestion. Manual of practise».- n. ${ }^{\circ} 16$.

Recibido: Julio 1997 Aceptado: Noviembre 1997 